\title{
Citizen Scientist: Farm 2 Facts Supporting Farmers Markets
}

\author{
Edna Ledesma ${ }^{1, * \mathbb{D}}$, Arden He ${ }^{2}$, Phillip Warsaw ${ }^{3} \mathbb{D}$, Lauren Suerth ${ }^{4}$, Alfonso Morales ${ }^{1}{ }^{\mathbb{D}}$, Leah Rosenblum ${ }^{5}$ \\ and Brian Wiedenfeld ${ }^{6}$
}

1 Department of Planning and Landscape Architecture, University of Wisconsin-Madison, Madison, WI 53706, USA; morales1@wisc.edu

2 Department of Economics, University of Wisconsin-Madison, Madison, WI 53706, USA; jhe264@wisc.edu

3 Department of Community Sustainability, Michigan State University, East Lansing, MI 48824, USA; warsawph@msu.edu

4 American Family Insurance, Madison, WI 53783, USA; lcsuerth@gmail.com

5 Gaylord Nelson Institute for Environmental Studies, University of Wisconsin-Madison Madison, Madison, WI 53706, USA; lrosenblum2@wisc.edu

6 Department of Agricultural and Applied Economics, University of Wisconsin-Madison Madison, Madison, WI 53706, USA; bwiedenfeld@wisc.edu

* Correspondence: eledesma@wisc.edu

check for updates

Citation: Ledesma, E.; He, A.; Warsaw, P.; Suerth, L.; Morales, A.; Rosenblum, L.; Wiedenfeld, B. Citizen Scientist: Farm 2 Facts Supporting Farmers Markets. Sustainability 2021, 13, 6162. https://doi.org/10.3390/ su13116162

\section{Academic Editors: Luis}

Jesús Belmonte-Ureña and

Mario D'Amico

Received: 3 April 2021

Accepted: 26 May 2021

Published: 30 May 2021

Publisher's Note: MDPI stays neutral with regard to jurisdictional claims in published maps and institutional affiliations.

Copyright: (C) 2021 by the authors Licensee MDPI, Basel, Switzerland. This article is an open access article distributed under the terms and conditions of the Creative Commons Attribution (CC BY) license (https:// creativecommons.org/licenses/by/ $4.0 /)$.

\begin{abstract}
As multifunctional loci of local food economies and public activity, farmers markets impart diverse impacts on their surrounding communities. In response to the emerging scholarship on farmers markets, as well as the desires of market managers to buttress their decision-making with cogent data analysis, the Farm 2 Facts data collection toolkit was created by the University of Wisconsin-Madison to measure the economic, social, and ecological impacts of farmers markets. We document here the history of Farm 2 Facts. Through case studies of F2F members, we describe the ways in which individual markets, market organizations, and local governments use farmers markets as a means of achieving differing goals, as well as how Farm 2 Facts necessarily adapted to measure and support these goals. We argue that Farm 2 Facts is in a tight reciprocal relationship with market managers who become citizen scientists in order to support their managerial role and communicate the benefits of their markets. Given that market policy change is often the impetus for collecting data, empathy for the goals of market managers is inseparable from Farm 2 Facts. We find that a sensitivity to the dynamic needs of markets, an adaptive toolkit, and incorporating ongoing research into the toolkit are essential to supporting farmers market managers in their many duties.
\end{abstract}

Keywords: farmers markets; citizen science; data collection; community impact analysis

\section{Introduction}

Whether in the dead of winter or the height of summer, managers of farmers markets are frequently very busy people. Market managers, vendors, and their stakeholders play important roles in communities around the country. Markets anchor small farmers, support local businesses, provide opportunities for entertainment and food access, and spread information of interest around the local community [1-4]. They are important to the community identity and help shape how a community thinks about itself $[5,6]$. With all of these functions in play, it is no wonder that managers are frequently asking for support in understanding market activities and making decisions about their markets and their relationships with the communities.

The same questions have echoed among farmers market managers for decades. "How do you organize your market? What vendors do we include? What rules should we have? How do we know we are successful? Maybe most importantly, how do I maintain strong relationships in my community and with my vendors ... ?" Managers seek answers on their own, with their immediate supporters, and with local allies. From the ground up, managers interpret, experiment with, and reinterpret their markets, their internal functions, and their 
roles in the external communities. Managers are, in effect, citizen scientists who assess and analyze their circumstances, consider organizational and individual attitudes and habits, and select decisions that they hope foster the goals of their market and community.

Government extension agents, college and university academics, and market managers themselves have sought to answer these questions. Market managers have often taken the initiative to create market management tools. Notable among these is Chris Quinlan, a former Canadian market manager whose software, Marketwurks, is now used in six countries to help market managers sort through vendor applications, determine where vendors should go in the market, and answer other organizational questions [7]. Beyond internal market structures, tools to help market managers develop a clearer understanding of the market's role in the external community have been lacking. This article elaborates the story of Farm 2 Facts, one such organization which has developed in response to market managers' needs.

In 2014, the University of Wisconsin-Madison's Department of Planning and Landscape Architecture founded the Kaufman Lab for the Study and Design of Food Systems and Marketplaces. Within the Kaufman Lab, the Farm 2 Facts (F2F) toolkit was created. As a robust set of research services to individual markets, market organizations, and other stakeholders, F2F is used by market managers, market organizations, and other organizations, such as city governments, for the purpose of citizen-driven decision-making. Farmers market managers implement the data collection tools on site at their markets and receive support from the F2F team of professionals and student researchers at the University of Wisconsin-Madison, who help make sense of the data. Farm 2 Facts's suite of services is wide and evolving, and it includes data collection, analysis, reporting, and consulting. These tools are developed at the request of managers with sensitivity to market manager feedback, and they recognize the historically diverse needs and goals of markets.

At the same time, the tools are rooted in pragmatism and interactionist social science, as well as ongoing research conducted at the lab and elsewhere. By democratizing sophisticated social science research tools, F2F has empowered a collection of farmers markets with self-collected data, making farmers market managers the "principal investigators" of their markets in an approach to social science research referred to as citizen science [8]. Observation, and hence science, is deeply human, namely in methods we call scientific discipline and refined observation. Pragmatist philosophy founded interactionist scientific methods that have been developed since the early twentieth century $[9,10]$. For these practitioners, systems of ideas and interactions framed by concepts like choice, habit, purpose, and role are among the key tools for theorizing human activities. People grasp and practice these conceptual tools out of habit, and thus, scientific interactionism is democratic, and reflection helps everyone be a citizen scientist. By developing and deploying tools that democratize data, F2F deepens the connections between academic researchers and local stakeholders, as well as between those stakeholders and their activities. In turn, these connections provide a range of potential benefits to all actors in the process, including providing avenues to more robust data than would otherwise be possible for researchers while allowing stakeholders to develop scientific literacy, an understanding of scientific processes like data collection, and how these apply to their own community.

In this article, we first summarize the citizen science literature as a bottom-up approach to data collection and contextualize it with research on farmers markets. We provide an overview of the history of the Farm 2 Facts toolkit. Then, we outline the methodological approach applied through the Farm 2 Facts model. Lastly, we argue how F2F serves as a model of the citizen science approach that centers the voices of market managers and market organizations in the decision-making process. F2F can empower the voices of the community and market mangers through a data collection platform that (1) integrates a bottom-up form of data collection, (2) allows for co-production of knowledge between market managers and the community, and (3) is flexible by adapting to context-specific metric and data collection needs. 


\section{Literature Review}

\subsection{Citizen Science}

Citizen science is, broadly, an ecosystem approach to data collection [10]. It is a research method where scientists and members of the public collaborate to study communities and ecosystems through systematic processes that produce reliable data on real world phenomena [10-14]. The objective is to increase both scientific and public understandings of issues spanning multiple scales by integrating applied perspectives and knowledge into the data collection, analysis, and data interpretation $[15,16]$. Citizen science is a broad term that people use to describe a range of research-oriented activities [10]. The method is not new, but it is gaining attention among scholars and practitioners as a bottom-up strategy for integrating local knowledge into scientific investigations that evaluate complex problems [10,17-19]. In our case of Farm 2 Facts, citizen science is a methodological approach of data collection that centers the voices of market mangers as the decision-making agents.

The research method was developed through two simultaneous yet independent origins. In the US, Rick Bonney used "citizen science" to describe projects where scientists engage members of the public to implement a formal research project. Scientists mobilize members of the public to collect and classify observational data, and they organize it into a large dataset. Participation is voluntary, but participants indirectly benefit by learning about the issue they are studying and the process for conducting a scientific investigation. In the UK, Alan Irwin used "scientific citizenship" to describe the need for opening up scientific research and politics to the public. Scientists collaborate with members of the public to formulate new knowledge that integrates local perspectives into investigations and make informed decisions. Projects democratize science to help communities collect data and influence timely policy processes and decisions. Between the two perspectives, citizen science is a method for doing research in and outside of traditional institutions and settings $[9,10,12,14,20]$. Contemporary projects either follow one perspective or combine elements of both. On one hand, the flexibility means that the method fulfills various informational needs and outcomes and that the perspectives are mutually supportive, but on the other, the many different applications have created a nebulous understanding of the method itself and contention over its characteristics and utility $[9,10,12,14]$. F2F is a tool that combines elements of both perspectives and engages with the public to make market managers and arguably furthers the literature of citizen science by demonstrating how applied research can have a direct impact on policies. In the context of this literature and the practices of day-to-day market management, we ask the following three research questions: (1) How are market managers like scientists? (2) Can we use citizen science to understand and support market manager activities? (3) How has Farm 2 Facts mirrored a model of citizen science that can serve data collection, analysis, reporting, and decision support for farmers markets?

\subsection{The Job of a Market Manager}

Farmers market managers (MMs) act on their values and goals in making decisions as they balance various stakeholder concerns. Market management, whether by individuals, committees, or government or private citizens, inherits and establishes relationships to places and people, as well as habits and organizational practices [21,22]. MMs frequently deal with thin resources and staff and are exposed to risk and change due to the dynamic physical and social nature of the open-air marketplace. They do not always have time to evaluate their activities' relationships and are forced to react to difficult situations and unforeseen opportunities. Though markets are constituted by their unique contexts, they are not limited to them. In all of this, managers are practicing values associated with who they are, what they do, and what they are working for.

People become managers for a variety of reasons. They are farmers needing to create an organization, consumers desiring healthy food, and employees of a university outreach program or city government [23]. They typically learn to adapt the perspectives and values of those they work with, and they recognize the importance of those relationships. Organiza- 
tional partners, whether government or private, provide markets a place to exist. Sometimes, they also provide an operating framework in terms of rules or regulations [21,22].

Farmers market managers implement tools that incorporate stakeholder interests. For instance, managers designate assigned spaces according to government regulations or market conventions [24] and review vendor applications in light of consumer needs and government regulations. Simultaneously, market managers exercise agency by discerning organizational choices that they can make to perpetuate goals in their markets. Academic authors and organizational actors provide examples of organizational and regulatory choices that support managers in this decision-making. For instance, the Vermont School of Law sponsors a legal tool kit for farmers markets [25]. Another example is the work of the Kaufman Lab at the University of Wisconsin-Madison, which developed organizational ideas and tools to support the Bloomington Indiana Farmers Market's interest in inclusivity [26].

However, stakeholder and market goals should not be opposed nor separated. Many decisions at the market can simultaneously fulfill consumer demand, perpetuate market manager values, and fulfill the goals of local governments and community organizations. Examples of this include programming entertainment or educational demonstrations at the market, seeking to enhance food security, or responding to social demands for sustainability. Some of these decisions are made on the basis of the managers' values or the interests or needs of the jurisdiction, and time and context matter. During and after these decisions, managers are evaluating their outcomes according to their expertise, interests, and needs.

MMs weigh and make choices in the midst of complex social, economic, organizational, and political contexts. For example, the Bloomington Indiana Farmers Market landed on the front page of The New York Times for a community uproar caused by an alleged white supremacist vendor [27]. MMs are also the beneficiaries of supportive social contexts. Volunteers, interested consumers, and local governmental and other organizations can all be important allies.

Certainly, economic and health realities present challenges and opportunities. For instance, in the early days of the COVID-19 pandemic, MMs were making the case for safe consumption in their outdoor spaces. In Wisconsin, MMs sought the help of the Department of Health Services, the Department of Agriculture, Trade, and Consumer Protection, and the University of Wisconsin-Extension. The process was wrought with misunderstandings and long waits, and while some markets were dismayed, many others persisted and were increasingly successful in supplying their communities with healthy food in safe environments [28].

Markets plot paths through and with organizational entities of various kinds. However, the web of conflicting beliefs and values in their ambient communities presents challenges and opportunities to managers of markets and market organizations. The decision-making processes they engage in are always a mix of politics and science, as well as values and data. Before the creation of F2F, the need was clear for a group of professionals to steer a middle path, fostering strong markets that invite participation from community members as well as befitting MM, stakeholder, and partner goals.

Over the decades, stakeholders have multiplied, and different interests have become salient. The increasingly important and diverse purposes of famers markets have reinforced the interest in and need for data collection. In the 1970s, people who wanted a farmers market were told to start one [29]. Many did, and markets began populating places where consumer demand met people with time and ability, which meant that in the 1980s, markets became common in middle class communities and suburbs. However, this began changing as food became of interest outside of marketing, nutrition, and production. The number of markets was growing and, while of no consequence to the grocery industry, the growth was of central interest to growers, and the U.S. Department of Agriculture (USDA) became interested in the related phenomena of organic products and "local" foods.

In the 1990s, the USDA began to document the number of farmers markets as scholars from a variety of disciplines became interested in marketplaces more generally [30]. Mar- 
ketplaces, once considered anachronistic, were returning to the mainstream consciousness, buoyed by interests in "antique" and found merchandise, widening income inequality, the need for inexpensive consumer items, the advent of the "foodie", and celebrity chefs sourcing from local farmers at local marketplaces. Various business and social science disciplines contributed to the growing presence of markets in the popular literature. Cities began "placemaking" initiatives around markets and considered them amenities as much as sources of consumer goods [20]. Marketplaces had always stimulated the artistic and poetic imagination, and once again, humanistic scholars and historians seriously examined the age-old activity in its many forms, including swap meets, farmers markets, street markets, and public markets.

By the 2000s, multifunctional markets became common, embraced by multiple perspectives and populations with goals both shared and distinct. Markets were slowly being embraced by and located in communities of color and were being used as policy tools [24]. Some policy objectives for farmers markets were obvious, as farmers markets support food security and food access. However, other goals were also emergent, such as fostering new farmers, increasing diversity in the farming profession, and place-based community development. Advocacy organizations supporting farmers markets emerged, mostly local and often with farmers markets as one of many activities, but focused state associations were also created, and in 2008, the Farmers Market Coalition emerged to represent markets around the country.

Unsurprisingly, some professionalization of market managers and organizations occurred, as well as increased interest in evaluating the needs of consumers, farmers, market managers, and others involved in the rapidly growing sector. This pressing need for data meant that organizations expanded their typical partners to include academics, who could help identify means to answer the needs or questions MMs had about their markets. Likewise, managers sought support with different social and legal elements of market organization, data collection, stakeholder management, and marketing.

Over the last decade, government policy and market decision-making needs have demanded the creation of data tools and consulting services. In the next section, we present an overview of the current trajectory of F2F by analyzing how the tool was developed to help MMs and market organizations in their decision-making processes.

\section{Materials and Methods}

\subsection{Development of Farm 2 Facts}

Farm 2 Facts (F2F) was born out of farmers market managers' demonstrated interest in data-driven decision-making. Research showed that those MMs were interested in legitimate and reliable tools that would be easy to use. After a long process of engagement between Farmers Markets Coalition (FMC) executive director Stacy Miller and Professor Alfonso Morales of the University of Wisconsin-Madison, Farm 2 Facts was created. The Miller/Morales relationship began with Miller's interest in supporting market managers. She won support from the USDA to convene a group of experts to survey MMs. This collaboration led to a successful USDA AFRI (Agriculture and Food Research Initiative) grant application (Indicators for Impact NIFA, 2014-68006-21857), which in turn delivered the beta test software platform Metrics and Indicators for Impact, which is now F2F.

Central to the USDA award was the idea that the academics would be at the service of the managers and would develop scientifically legitimate and reliable tools based on the experience of market managers. In effect, the team flipped the typical relationship between town and gown; the academics became the research assistants to the markets. The University of Wisconsin-Madison hosted this developmental process in collaboration with the Farmers Market Coalition. Morales and his graduate and undergraduate students in the Kaufman Lab (notably, co-founder Lauren Suerth, PhD 2018) evaluated the science to facilitate market manager collection, analysis, and use of data to drive decisions and support partnerships. The UW team included professional software coders at the university, who built the web application and supervised undergraduate learning experiences to create 
software able to be adapted for many purposes and incorporate new variables. Vital to managers, the software allows the user to make comparisons over time, whether of markets against other markets within an organization or markets against themselves over time.

The F2F tools are administered at Kaufman Lab within the University of WisconsinMadison as part of the public service mission of the university, known as the Wisconsin Idea. As a non-profit, the tools and consulting services are billed to members on a cost recovery basis. Initially, F2F was oriented toward data collection, analyses, and reporting. The only consulting service available was for custom economic analyses. Today, F2F has expanded to include data collection processes for both paper-based and web-based data collection, interpretive statements for each metric, the ability to compare metrics within and between markets over time, tableau-style graphics, customizable infographics, grant or report writing, geospatial analyses, and marketing support for markets and market organizations. The evolution of F2F's services, as demonstrated in the following section, was a direct response from the research team to MMs' stated needs. The boundaries of F2F as a service are permeable and increasingly wide. Due to its experimental nature as a program born from a research lab, as well as the range of expertise among the concurrent F2F employees and Kaufman Lab members, the services of F2F are emergent. F2F member markets and market organizations are often the initiators as well as the beta testers of new metrics.

These services won immediate interest in the U.S. and Canada, and F2F became a subcontract on a number of grant awards. Since its development, F2F has expanded its reach beyond Wisconsin to twelve states in the U.S. and one Canadian province. Figure 1 shows the number of market partners by state. Over time, the F2F toolkit and team has grown to provide customized marketing support, custom data analysis, custom metric creation, support in market design and placemaking for cities and towns, as well as continued scientific development, policy work, and specialized data collection to support the local food sector and farmers markets in particular. In short, F2F is now a one-stop shop for many types of needs market managers have.

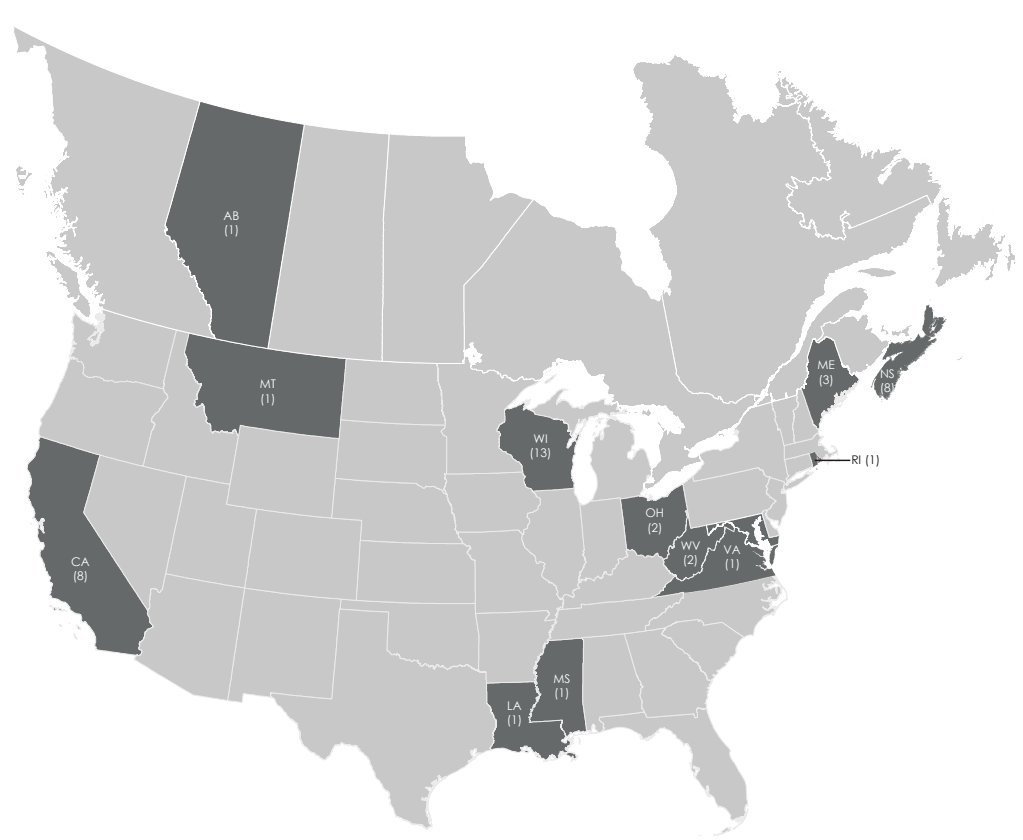

Figure 1. Total number of F2F market partners by state and province in the U.S. and Canada.

\subsection{Case Study Analysis}

Human behavior analysis requires context-specific study, and case studies are a type of context-dependent form of knowledge production [31,32]. As a qualitative method, the use of case studies allows researchers to explore complexities beyond the scope of a more 
controlled approach [31]. The closeness of the case study to real-life situations and its wealth of details are important in the development of a nuanced view of reality, including the view that human behavior is not easy to simplify [33]. A key characteristic of case studies is the use of multiple sources of evidence [31]. The case study is a main method that holds different sub-methods within, such as interviews, observations, document and record analysis, and so on [31]. Case studies are useful for both generating and testing hypotheses, but they are not limited to these research activities alone [33]. One advantage of the case study is that it allows for a closing-in of real-life situations and test views directly in relation to phenomena as they unfold in a place [33].

This paper seeks to analyze how farmers market managers engage in citizen science, the value of a bottom-up data collection software platform in facilitating that work, and the resulting knowledge that is co-created from its use. As a case study, we used the total number of markets that were enrolled in Farm 2 Facts as of 2019. We utilized both internal Farm 2 Facts documents, including market applications and market reported data, as well as external documents and news reports to identify common themes among the participating markets in their utilization of Farm 2 Facts to advance their communitybased goals.

\section{Results}

The following section illustrates the ways F2F has adapted itself to empower market managers, market organizations, and jurisdictions hosting markets. Often, though not always, the most immediate entities shaping the presence of the market in the local food economy are market managers, market organizations, and government jurisdictions. As the number of stakeholders has multiplied, and as data collection has become associated with action, the need for flexible measurement has increased. The balance of powers in the local food economy differs from place to place. F2F is conscious of this balance and forms close relationships with markets to adapt to their specific community roles.

\subsection{Supporting Market Managers}

Individual markets are often important elements of a small-town, downtown, or urban neighborhood, and Farm 2 Facts was originally designed with the managers of these markets in mind. Farmers markets can act as focal points for local food, where other food organizations and programs gain visibility. More generally, markets are public gathering spaces serving the unique interests of each community. Due to their wide range of possible purposes, flexibility and close relationships with the markets are necessary when attempting to measure their impacts. This flexibility includes recreating aspects of the F2F software, as well as looking beyond the software when conducting the evaluation.

Farm 2 Facts empowers market managers of individual markets to be citizen scientists. For example, the South Milwaukee Downtown Market (SMDM) is an attraction nestled in a high-density commercial area. The market boasts many community events, such as live music and seasonal festivals, and it hosts over a dozen local nonprofits. The SMDM joined as a member of Farm 2 Facts in 2018 and is still an active member. Using F2F, the SMDM produced a 2019 report that compared visitor counts and demographics, market sales, and vendor attendance from 2018 to 2019.

Beyond following F2F's premade instructions for data collection, market mangers have the opportunity to contribute to the design of the metrics. The SMDM's market manager was particularly active in the implementation of Farm 2 Facts. Prior to F2F, the SMDM did not collect market data. Farm 2 Facts' weekly Q\&A sessions for members provided live support for the market manager, and F2F researchers received her feedback about software features. Farm 2 Facts formed a close relationship with this member and implemented many of the MM's suggestions. These updates included edited instructions, the introduction of visualization features, and a new metric for the highest-frequency visitors' zip codes. 
In other cases, the farmers market may be a subsidiary project of a larger food hub organization. These markets often inherit the goals and funding of their parent organizations, allowing them to host a range of programs rarely seen at independent markets. Therefore, flexible measurement and a close ear to the ground are necessary to capture their true impact. Hope and Main $(\mathrm{H} \& \mathrm{M})$ is a large kitchen incubator and food hub in Warren, Rhode Island, hosting over a hundred small food businesses. H\&M joined F2F in 2018, when F2F was subcontracted on a larger USDA grant that supported an evaluation of H\&M's impacts in its region. H\&M hosts the Schoolyard Market, which features a mix of H\&M entrepreneurs and other vendors. Community events such as fundraisers, dinner parties, and talks are often held either in the market space or inside the H\&M building. Placemaking is a priority for the Schoolyard Market; live music, zany decorations, and handwritten signs are all curated to make the market approachable to all visitors.

H\&M has an orientation toward local food and food justice, and they support other community organizations and governmental departments who share those goals. In 2020, H\&M raised money during the COVID-19 crisis to distribute school meals and to prepare free meals for all local families in need. In both cases, the Schoolyard Market was the pickup point for meals. H\&M intentionally pivoted from the bought-in-bulk, processed meals that the school district was providing. Instead, their free meals included culinary variety and fresh produce from local producers, with the goal of providing "real food" to communities who are often offered heavily processed food. Community organizations who were also interested in providing free meals joined with Hope and Main, including the Warren Senior Center and the Women's Resource Center.

Hope and Main's market is clearly instrumental to H\&M's mission of closing the gap on the local food chain. The Schoolyard Market is subsumed by an entity which is both multifaceted in its aims and large in capacity; the market offers unique programs not found at smaller farmers markets. The meals distributed at the market do not show up in market revenue or expenses, which renders them invisible to the default F2F software. Because of this, the orientation of F2F toward close relationships and holistic measurements is essential. F2F extended their evaluation of the Schoolyard market beyond the quantitative metrics included in the software. An F2F researcher conducted interviews with the Schoolyard Market's manager, H\&M employees, H\&M member businesses, and personnel from external collaborators. In an ongoing evaluation, F2F seeks to capture the importance of the Schoolyard Market with both qualitative and quantitative data. This description of the farmers market will, of course, be shaped by H\&M's much broader presence in the community.

\subsection{Supporting Market Organizations}

Market organizations play an important role in coordinating farmers markets and advancing larger-scale food security, economic development, and sustainability goals within a city or region. Farm 2 Facts is currently in collaboration with market organizations across the United States and Canada.

During times of widespread distress, market organizations can mobilize their individual markets to test solutions and present an example for other markets. For example, Agricultural Community Events Farmers' Markets (ACEFM) is a market organization made up of 10 markets located in Sonoma and Marin County, California (Figure 2). Farm 2 Facts was subcontracted on a grant application ACEFM sent to the USDA in 2020, in which they proposed a program to increase the reach of farmers markets in the midst of COVID-19 and the Sonoma County fires. They intended to promote new infrastructures that would benefit communities during rolling blackouts, earthquake recovery, and flooding events. In addition to curbside delivery for vendors at the market, ACEFM also intended to increase access for low-income communities through food hub drop-off points, since the electronic benefits transfer (EBT) program at the physical market was no longer as feasible. F2F tools enable comparative understanding of outcomes across markets. Like the Hope \& Main 
example, Farm 2 Facts is an essential tool for evaluating the impacts of the organization's proposed program and therefore is also necessary for the success of a grant application.

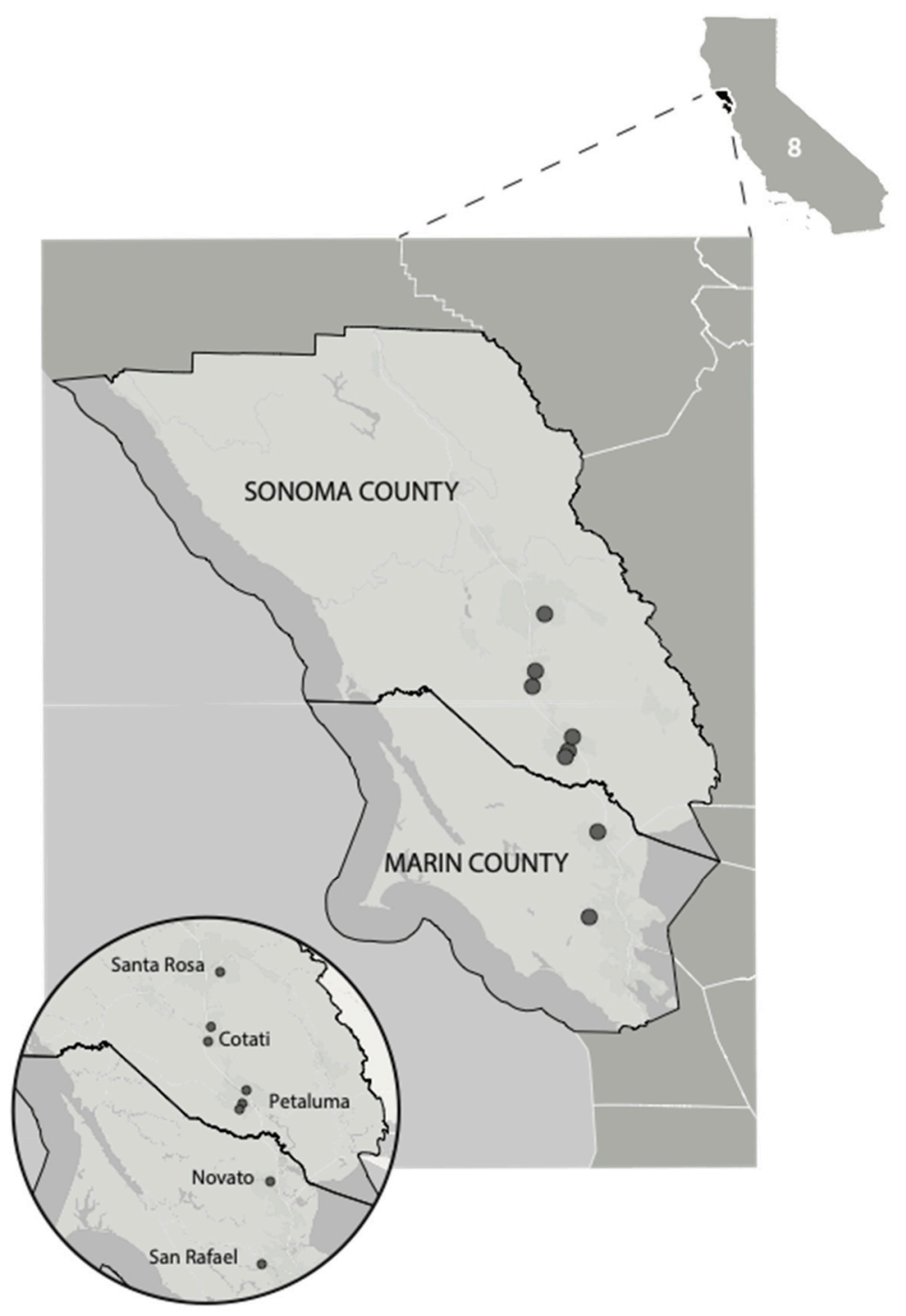

Figure 2. Locations of markets in ACE Farmers Markets.

Central Rivers Farmshed presents another example of F2F working with market organizations to build capacity at the local level. The organization emerged in 2006, when interest in local food was just beginning to climb in central Wisconsin. Around that time, discussions began to conceptualize food as a policy tool which could bring value to many different demographics. Community members hosted public forums alongside experts in 2007 and 2008 that sparked the popularity of regional food system development. Out of the forums, a local food organization was born called Central Rivers Farmshed. Early on, Central Rivers Farmshed was run by passionate volunteers. As the market organization's needs have grown, paid staff who now manage the organization's operations lack the capacity to meet their organization's goals.

Through an ongoing partnership with Central Rivers Farmshed, UW-Stevens Point, and UW-Extension, F2F is developing a program to embed local food more deeply into local values. Existing sources of local, fresh produce, such as farmers markets, are scattered. A lack of civic investment toward local food initiatives slows the progress of addressing food insecurity and inaccessibility $[34,35]$. Though available at many farmers markets, the benefits of the Supplemental Nutrition Assistance Program (SNAP) are primarily used 
at grocery stores, which leads to economic leakage out of the local economy and into a stretched national supply chain. The basic program, which was created to combat food insecurity by supporting local food initiatives, follows an example from previous work Farm 2 Facts conducted at the Brown Deer Farmers Market. Researchers at Kaufman Lab discovered that knowledge of SNAP benefits at the market was a primary barrier to local food accessibility. F2F intends to establish community connectors (CCs) across central Wisconsin, who will build connections on behalf of the market throughout the community and raise awareness about farmers markets.

Following the principles of citizen science, Farm 2 Facts pursues community action and novel research in tandem. The program with Central Rivers Farmshed is an applied research program as well as a food security program. Upon joining, members of F2F agree to have their data be used (anonymously) for research purposes, and market organizations in particular provide a rich source of data. As a market organization serving a wider geographic region, ACEFM sustains partnerships with the counties of Sonoma and Marin. The number of markets and the areas they span generate a useful amount of data. ACEFM is one of several large market organizations which provides historical sales data to F2F. The reciprocal relationship between Farm 2 Facts and the Kaufman Lab means that while research informs the product, the data collected by the toolkit also serve research purposes.

\subsection{Supporting Local Jurisdictions}

Government jurisdictions may explicitly view markets as tools for achieving food security and implement programs at the market to address local concerns. Farm 2 Facts is equipped to measure the context-specific outcomes of these programs and has previously aided in their implementation. For instance, the Brown Deer Farmers Market is financially supported by the village of Brown Deer, Wisconsin, and the market is overseen by a village administrator. The village of Brown Deer reports a relatively high black and low-income population compared with other areas in Wisconsin, two groups which are historically underrepresented as visitors of farmers markets [36]. This is not unique to Wisconsin farmers markets, as predominately non-white neighborhoods across the nation have significantly less access to fresh fruits and vegetables [35]. In a collaboration with Farm 2 Facts and the Kaufman Lab, the village measured and increased local food access for local underserved populations through the Brown Deer Farmers Market.

The Brown Deer Farmers Market was originally a research site for Chloe Green, a former student at UW-Madison working for Farm 2 Facts. Following her survey of food access across farmers markets in Wisconsin, Green made a proposal to American Family Insurance to conduct a food security program at the Brown Deer Farmers Market (BDFM). The market appointed a market access coordinator (MAC) to conduct community outreach at schools, senior centers, and low-income apartments and created marketing materials promoting the availability of SNAP at the market. The program attracted the donations of various organizations operating in the community, such as UW-Extension's FoodWise and the Children's Community Health Plan.

Farm 2 Facts was used to collect baseline data and post-treatment data. The EBT sales data collected by F2F were a primary point for evaluating the success of the program. F2F demonstrated a stunningly high increase in the percentage of SNAP sales, with the net percentage increase being over $500 \%$. Similar results have been seen nationwide, as promotion of SNAP usage at farmers markets is associated with significant increases in produce consumption [34]. The Kaufman Lab also used F2F data to estimate the economic impact of the program with the Local Food Economic Impact Calculator, which was designed in part by members of the lab. Farm 2 Facts employees who were concurrently employed at the Kaufman Lab supported the project, meaning the same people were involved in the program's implementation and technical evaluation. This overlap proved to be crucial to the success of both aspects. Difficulties with data collection meant that hands-on troubleshooting was required, which was fulfilled during Green's in-person visits to the market. As lab members were confronted with missing and incorrect data at the end 
of the program, they were able to reconstruct a timeline for the data based on experiences gleaned from the program's implementation phase.

\section{Discussion: A Flexible Toolkit}

Farm 2 Facts' flexible tools, stable partnerships, and orientation toward citizen science produces reciprocal relationships that enable new capabilities in managers, broaden the capacities of F2F, and extend the use of F2F software to related purposes. Throughout the years, Farm 2 Facts has extended its services beyond data collection and analysis.

\subsection{Market Evaluation}

For some markets, the goal of accurate data collection may be sufficiently met by the F2F software. For other markets, the formulaic interpretations generated by the F2F software may not capture the most relevant aspects of their market, and further work is required on the data collected. To support market managers and their goals in their communities, F2F has collaborated with market managers and organizations to develop new modes of evaluation. New forms of evaluation include conducting economic impact analyses, writing customized reports, advising on market design, and developing and executing marketing campaigns. The consulting services of Farm 2 Facts can be divided into two broad categories: impact and marketing.

\subsubsection{Impact Analysis}

Farm 2 Facts partners with member markets to produce reports of their economic and community impact. For example, as part of a national pilot study, F2F produced an annual report of the Fond du Lac Farmers Market from 2015 to 2017. The report included a visitor and vendor profile, analysis of customer spending and the reach of low-income customers, and an estimated economic impact. Similarly, while subcontracted on a USDA Farmers Market Promotion Program grant with REAP Food Group, Farm 2 Facts produced a report of 11 participating markets. Like the Fond du Lac report, the REAP report used F2F-collected data to generate an economic impact analysis for markets with sufficient data.

The REAP report exemplifies a problem with F2F, which is that few F2F-registered markets collect data. Only 4 out of 11 markets collected enough data for analysis. The REAP report was in part an evaluation of Farm 2 Facts and detailed common obstacles to data collection. The report concluded that invested markets were necessary to the efficacy of F2F, given that $\mathrm{F} 2 \mathrm{~F}$ requires the user to collect data and institute market practices that facilitate data collection. Besides the responsibility of market managers to collect and input data, vendors who safeguard their privacy are sometimes hesitant to give data to a faceless organization. The F2F research team has learned that data collection is an ongoing problem. Previous steps F2F has taken to mediate this include revising instructions, adding disclaimers about privacy, providing more live customer support, and offering multiple ways to enter data. The adaptivity of F2F will aid ongoing efforts to increase user participation.

\subsubsection{Marketing and Graphic Design}

Marketing and rebranding campaigns are among the few services offered by Farm 2 Facts. While these have little overlap with the Kaufman Lab research, they are essential aspects of market manager experimentation and action on the knowledge of their market. In 2020, Farm 2 Facts signed marketing contracts with two marketing organizations.

Since 2019, the F2F team has expanded to include expertise in graphic design, marketing, and project planning. The marketing contracts signed in 2020 entail market rebranding, fundraising research, competitive analyses, digital marketing, and market outreach. A graphic designed in the lab won a national award for food security graphics, given by the Farmers Market Coalition in 2018. 


\subsection{Metric Development}

In recognition of the multifunctional purpose of markets, Farm 2 Facts is continually in the process of developing new metrics. Often, single metrics come directly from member suggestions. For example, the market manager of Farmers Markets of Nova Scotia (FMNS) suggested that F2F capture the impact of LGBTQ+ farmers. F2F subsequently created a beta version of an LGBTQ+ vendor metric, which is exclusively available to FMNS markets. Larger suites of metrics are long-term projects usually generated by research interests within Farm 2 Facts. Two major examples of these are described below.

\subsubsection{Ecosystem Services Metric}

Farmers market managers and direct-market farmers seek to demonstrate interest in intractable problems and represent the direct market sector. They recognize that their operations can meet both economic and ecological sustainability goals. Direct-market producers cite ecological benefits as a major factor in their choice to sell directly to consumers [36]. Additionally, the health of the environment, humans, and animals seem to be connected to the motivations for farmers' practices. These values are reiterated in F2F's collaboration with producers and market managers. Partners of F2F expressed interest in the ability to calculate the ecological contributions of farm practices and communicate this to consumers, which sparked the development of an ecosystem services (ES) metric to measure the on-farm ecological footprint.

While economic viability is easily quantifiable, it is less straightforward to determine the value of better farm practices in terms of ecosystem services. Existing ecological footprint calculators lack user-friendly interfaces and are not explicitly designed for directmarket farmers. By collecting feedback from a range of farmers and farm types, F2F has been designing an ES metric which is more accessible and applicable to a variety of farmers. The F2F ES metric collects data from farmers on their practices in order to measure their ES output and potential for improvement. The ES metric will support farmers in marketing their practices and eventually assist in policy creation for governments to reward ES practices outside of the market.

\subsubsection{Farm to Hospital}

Local foods are increasingly important and of interest to institutions as a whole. We self-consciously adopted software coding techniques that made the F2F software adaptable to other local food practices. For instance, we won an Institute for Clinical and Translational Research (ICTR) grant for adapting F2F to institutional uses. These tools have growing applications for organizations and institutions within other alternative agrifood networks (AAFN). Community-based institutions such as schools and hospitals have significant purchasing power to generate local and regional economic impact [37-40], have the leverage to influence consumer behavior through their growing retail presence [41-44], and have social missions which align with a strategy of local food procurement $[36,45,46]$. However, these organizations also often face organizational constraints, such as limited budgets and the entrenched thinking that foodservice is solely a means to generate revenue and not a means to improving educational or public health outcomes [46].

Countering these dynamics requires, in part, demonstrating the non-revenue impact that procurement and promotional strategies can have on local communities. Previous research has indicated that communicating the value of local food purchasing, specifically its local economic impact, can generate support from vital stakeholders, including local policymakers [47]. However, collecting the necessary data for robust impact analysis can be taxing for institutional stakeholders [48]. The offshoot of F2F funded by the ICTR grant, called F2F-HC, can address this gap by providing stakeholders with a lean data approach to data collection and analysis. 


\section{Conclusions}

As we have shown, citizen science is a methodological approach of data collection that centers the voices of market mangers as the decision-making agents through the Farm 2 Facts model. In the practices of day-to-day market management, we explored how market managers were like scientists. The case studies demonstrate that F2F is a tool that provides bottom-up knowledge for decision-making. We demonstrated that citizen science can be used to understand and support market manager activities, such as when operating EBT programs at farmers markets and increasing outreach. Indeed, Farm 2 Facts mirrored a model of citizen science that can serve data collection, analysis, reporting, and decision-support for farmers markets.

Over the past several years, farmers markets, market organizations, and governmental organizations in the United States and Canada have successfully implemented tools for data collection that empower markets and their surrounding communities. These tools, including Farm 2 Facts, are scientifically based and support citizen scientists seeking to identify and achieve the many goals farmers markets make possible. Marketplaces are multifunctional opportunities to build communities, support the economy, foster more civil societies, and create inclusive and productive places.

Central to supporting different types of organizations is responding to the dynamic needs of markets. Program funding and data reporting feed into one another, which means that the realization of market goals often requires data collection. In F2F, the components of analysis and implementation are vertically integrated. Farm 2 Facts partners with markets to write grants, create and teach data collection methods, design and implement funded programs, and evaluate those programs. The shifting goals of markets entail rapid adjustments to each responsibility. The presence of a single organization which understands and shapes each component allows for fast adaptation.

Software tools by themselves can produce useful measurements, but the social relationships behind Farm 2 Facts are what make it particularly useful to communities seeking to leverage farmers markets for the many purposes they can serve. F2F professionals form close relationships with practitioners to identify immediate needs and detect many emergent needs. The measurement of a single unit implies an understanding of the system enclosing that unit. We work closely with market managers to understand their goals in the context of community dynamics. These goals include characterizing market demographics, increasing community food security, and tightening market operations. Rarely are market goals singular, which is reflected in our adaptive approach.

Moving forward, the research team at the Kaufman Lab will continue to learn as they respond to farmers markets and market organizations in their particular contexts and communities. This knowledge will support these actors in meeting their unique goals. In a few years, F2F has reached 44 farmers markets across eleven states in the U.S. and one province in Canada. In 2021, our member network will expand to markets and related organizations in Michigan, New York, and Texas. Our flexible tools are also being adapted to support hospitals in understanding their community impact through their work with local foods. Most importantly, new scholars and students are emerging to respond to needs in the field in the years ahead.

Author Contributions: Conceptualization, E.L. and A.M.; literature review, L.S., E.L., and A.M.; methodology, A.M., P.W., A.H., E.L., L.R., and B.W.; writing—original draft preparation, A.M., A.H., P.W., E.L., L.R., and B.W.; writing-review and editing, A.H.; supervision, A.M. and E.L. All authors have read and agreed to the published version of the manuscript.

Funding: This research received no external funding.

Institutional Review Board Statement: Ethical review and approval were waived for this study, due to minimal risk of study.

Informed Consent Statement: Not applicable.

Data Availability Statement: Data sharing non applicable. 
Acknowledgments: Megan Sankey, an undergraduate student at UW-Madison, contributed to the literature review and selected article citations and edits. Anna S. Feldman, an undergraduate at UW-Madison, contributed to the literature review. Garrett Smith of UW-Madison Teaching \& Research Application Development, as well as Rachel Fu, Mary Frances Shaugnessy, and Sam Owen, undergraduates at UW-Madison, developed the F2F software described in this paper.

Conflicts of Interest: All authors are or were previously creators or employees of Farm 2 Facts.

\section{References}

1. Balkin, S. Self-Employment for Low-Income People; Praeger: New York, NY, USA, 1989; ISBN 978-027-592-807-0.

2. Balkin, S.; Mier, B. Maxwell Street: Chicago Illinois. In Celebrating the Third Place: Inspiring Stories About the "Great Good Places" at the Heart of Our Communities; Oldenburg, R., Ed.; Marlowe \& Co: New York, NY, USA, 2001; pp. 193-208, ISBN 156-924-612-2.

3. Jacobs, J. The Death and Life of Great American Cities; Random House: New York, NY, USA, 1961; ISBN 978-039-442-159-9.

4. Maisel, R. The flea market as an action scene. J. Contemp. Ethnogr. 1974, 2, 485-505. [CrossRef]

5. Project for Public Spaces; Partners for Livable Communities. Ford Foundation Research: Public Markets as a Vehicle for Social Integration and Upward Mobility. Available online: http:/ / www.pps.org/pdf/Ford_Report.pdf (accessed on 16 January 2021).

6. Spitzer, T.M.; Baum, H. Public Markets and Community Revitalization; The Urban Land Institute and Project for Public Spaces: Washington, DC, USA, 1995; p. 121, ISBN 087-420-764-9.

7. Marketwurks. Marketwurks-Modern Farmers Market Software. Available online: https://marketwurks.com/ (accessed on 2 February 2021).

8. Suerth, L. Citizen Participation \& Actionable Knowledge in Food Systems Practice. Ph.D. Thesis, University of WisconsinMadison, Madison, WI, USA, 2019.

9. Morales, A. Pragmatism's Mundanity: Epistemic Foundations for a Practicing Socio-legal Science. In Review of Realistic Socio-Legal Theory; Tamanaha, B., Ed.; Oxford University Press: Oxford, UK, 1998; Volume 32, pp. 493-514.

10. Morales, A. Food Systems: (Im)practical Interactions. Pluralist 2019, 14, 21-46. [CrossRef]

11. Bonney, R.; Cooper, C.B.; Dickinson, J.; Kelling, S.; Phillips, T.; Rosenberg, K.V.; Shirk, J. Citizen Science: A Developing Tool for Expanding Science Knowledge and Scientific Literacy. BioScience 2009, 59, 977-984. [CrossRef]

12. Davies, L.; Fradera, R.; Riesch, H.; Lakeman-Fraser, P. Surveying the citizen science landscape: An exploration of the design, delivery and impact of citizen science through the lens of the Open Air Laboratories (OPAL) programme. BMC Ecol. 2016, 16, 17. [CrossRef]

13. McKinley, D.C.; Miller-Rushing, A.J.; Ballard, H.L.; Bonney, R.; Brown, H.; Cook-Patton, S.C.; Soukup, M.A. Citizen science can improve conservation science, natural resource management, and environmental protection. Biol. Conserv. 2017, 208, 15-28. [CrossRef]

14. Riesch, H.; Potter, C. Citizen science as seen by scientists: Methodological, epistemological and ethical dimensions. Public Underst. Sci. 2014, 23, 107-120. [CrossRef]

15. Ellwood, E.R.; Crimmins, T.M.; Miller-Rushing, A.J. Citizen science and conservation: Recommendations for a rapidly moving field. Biol. Conserv. 2017, 208, 1-4. [CrossRef]

16. Loss, S.R.; Loss, S.S.; Will, T.; Marra, P.P. Linking place-based citizen science with large-scale conservation research: A case study of bird-building collisions and the role of professional scientists. Biol. Conserv. 2015, 184, 439-445. [CrossRef]

17. Chandler, M.; Rullman, S.; Cousins, J.; Esmail, N.; Begin, E.; Venicx, G.; Studer, M. Contributions to publications and management plans from 7 years of citizen science: Use of a novel evaluation tool on Earthwatch-supported projects. Biol. Conserv. 2017, 208, 163-173. [CrossRef]

18. Ottinger, G. Buckets of Resistance: Standards and the Effectiveness of Citizen Science. Sci. Technol. Hum. Values 2010, 35, 244-270. [CrossRef]

19. Silvertown, J. A new dawn for citizen science. Trends Ecol. Evol. 2009, 24, 467-471. [CrossRef] [PubMed]

20. Kullenberg, C.; Kasperowski, D. What Is Citizen Science?-A Scientometric Meta-Analysis. PLoS ONE 2016, 11, 1-16. [CrossRef] [PubMed]

21. Fisher, A. Hot Peppers and Parking Lot Peaches: Evaluating Farmers' Markets in Low Income Communities; Community Food Security Coalition: Venice, FL, USA, 1999.

22. Tiemann, T.K. Grower-only farmers' market: Public spaces and third places. J. Popul. Cult. 2008, 41, 467-487. [CrossRef]

23. Ragland, E.; Tropp, D. National Farmers Market Manager Survey; United States Department of Agriculture: Washington, DC, USA, $2009 ;$ p. 100.

24. Morales, A.; Kettles, G. Zoning for Public Markets and Street Vendors. Zoning Pract. 2009, 25, 1-8.

25. Center for Agriculture \& Food Systems. Farmers Market Legal Toolkit. Available online: https://farmersmarketlegaltoolkit.org/ (accessed on 2 February 2021).

26. Farm 2 Facts. How to Increase Inclusivity \& Diversity at Your Farmers Markets. Available online: https://farm2facts.org/howto-increase-inclusivity-diversity-at-your-farmers-market/ (accessed on 2 February 2021).

27. New York Times. Amidst the Kale and Corn, Fears of White Supremacy at the Farmers' Market. Available online: https: //www.nytimes.com/2019/08/18/us/indiana-farmers-market-white-supremacy.html (accessed on 2 February 2021). 
28. Morales, A. Co-Producing Safe Farmers Markets During COVID-19. University of Pennsylvania Law School. Regul. Rev. Available online: https: / / www.theregreview.org/2020/07/28/morales-co-producing-safe-farmers-markets-covid-19/ (accessed on 24 May 2021).

29. Friedlander, H. If you want to be a customer at a farmers' market-start one. Org. Gard. Farming 1976, 23, 108-109.

30. Morales, A. Marketplaces: Prospects for Social, Economic, and Political Development. J. Plan. Lit. 2011, 26, 3-17. [CrossRef]

31. Gillham, B. Case Study Research Methods; Bloomsbury Publishing Plc: London, UK, 2000.

32. Flyvbjerg, B. Five Misunderstandings About Case-Study Research. Qual. Inq. 2006, 12, 219-245. [CrossRef]

33. Chase, J.; Craford, M.; John, K. Everyday Urbanism; Monacelli Press: New York, NY, USA, 2008.

34. Freedman, D.A.; Vaudrin, N.; Schneider, C.; Trapl, E.; Ohri-Vachaspati, P.; Taggart, M.; Cascio, M.A.; Walsh, C.; Flocke, S. Systematic Review of Factors Influencing Farmers' Market Use Overall and among Low-Income Populations. J. Acad. Nutr. Diet. 2016, 116, 1136-1155. [CrossRef]

35. Lowery, B.; Sloane, D.; Payán, D.; Illum, J.; Lewis, L. Do Farmers' Markets Increase Access to Healthy Foods for All Communities? Comparing Markets in 24 Neighborhoods in Los Angeles. J. Am. Plan. Assoc. 2016, 82, 252-266. [CrossRef]

36. Brown, A. Farmers' Market Research 1940-2000: An Inventory and Review. Am. J. Altern. Agric. 2002, 17, 167-176. [CrossRef]

37. Albrecht, C.; Smithers, J. Reconnecting through local food initiatives? Purpose, practice and conceptions of 'value'. Agric. Hum. Values 2018, 35, 67-81. [CrossRef]

38. Dubb, S.; Howard, T. Leveraging anchor institutions for local job creation and wealth building. Big Ideas For Job Creation 2012, 4-12. Available online: https:/ / community-wealth.org/sites/clone.community-wealth.org/files/downloads/paper-dubb-howard.pdf (accessed on 15 November 2020).

39. Koh, H.K.; Bantham, A.; Geller, A.C.; Rukavina, M.A.; Emmons, K.M.; Yatsko, P.; Restuccia, R. Anchor institutions: Best practices to address social needs and social determinants of health. Am. J. Public Health 2020, 110, 309-316. [CrossRef] [PubMed]

40. Klein, K. Values-based food procurement in hospitals: The role of health care group purchasing organizations. Agric. Hum. Values 2015, 32, 635-648. [CrossRef]

41. Food Service Director. 2016 Healthcare Census: Hospitals Raise Their Game. Available online: https:/ / www.foodservicedirector. com/operations / 2016-healthcare-census-hospitals-raise-their-game (accessed on 30 October 2020).

42. Guillaumie, L.; Boiral, O.; Baghdadli, A.; Mercille, G. Integrating sustainable nutrition into health-related institutions: A systematic review of the literature. Can. J. Public Health 2020, 111, 1-17. [CrossRef] [PubMed]

43. Mamidi, R.S.; Kulkarni, B.; Radhakrishna, K.V.; Shatrugna, V. Hospital based nutrition rehabilitation of severely undernourished children using energy dense local foods. Indian Pediatr. 2010, 47, 687-693. [CrossRef]

44. Warsaw, P.; Morales, A. The Potential Impact of Hospital Cafeterias on Dietary Habits: A Case Study of the University of Wisconsin Hospitals and Clinics. WMJ Off. Publ. State Med. Soc. Wis. 2020, 119, 122-125.

45. Klein, K.; Michas, A. The farm fresh healthcare project: Analysis of a hybrid values-based supply chain. J. Agric. Food Syst. Community Dev. 2014, 5, 57-74. [CrossRef]

46. Sachs, E.; Feenstra, G. Emerging Local Food Purchasing Initiatives in Northern California hospitals. Available online: https: //www.noharm.org/documents/emerging-local-food-purchasing-initiatives-northern-california-hospitals (accessed on 30 October 2020).

47. Rahe, M.L.; Van Dis, K.; Gwin, L. Communicating Economic Impact Assessments. J. Agric. Food Syst. Community Dev. 2019, 8, 95-105. [CrossRef]

48. Dichter, S.; Adams, T.; Ebrahim, A. The Power of Lean Data. Available online: https://ssir.org/articles/entry/the_power_of_ lean_data\# (accessed on 15 November 2020). 